\title{
Planning more research on AIDS
}

\author{
The US Public Health Service has found an extra pot of gold for research on AIDS. \\ Luckily, there is also now an agenda for making use of it.
}

IT is natural enough that the US Public Health Service should have responded to public concern about acquired immune deficiency syndrome (AIDS) by throwing a modest amount of money at the problem (see page 365). The volume of correspondence (some of which appears on page 371) stimulated by a previous article on the subject (see Nature 28 April, p.749) is but one sign of how the unexpected appearance in the past few years of this bizarre disease has provoked a sense of nightmare. So how should the US Public Health Service spend its extra $\$ 14.5$ million?

Two features of what little is known of AIDS stand out. First, it occurs predominantly among male homosexuals and their sexual contacts of either sex, among certain ethnic groups (Haitian immigrants to the United States for example) and among haemophiliacs dependent on blood products for their survival. Second, because the root cause of the disease seems to be to render incompetent a class of cells (T-helper cells) essential for normal cellmediated immunity, people with AIDS are usually recognized when they acquire some other disease, the otherwise unusual pneumonia Pneumocystis carinii caused by a protozoan organism or Kaposi's sarcoma, an otherwise uncommon skin cancer, for example. Because the T-cell population seems to be damaged irreversibly, mortality is high.

The nightmarish connotations of AIDS stem, however, not from the high mortality among those affected, for the incidence of the disease is not high even within the groups apparently susceptible to it, but from what has hitherto been sheer ignorance of the cause. Inevitably, in the past several months, people have been coming to the conclusion that there must be a transmisible agent and that the agent could well be a retrovirus (see Nature 28 April, p.749). One obvious model for such an agent has been the only virus so far known to be implicated in the transmission of malignan$\mathrm{cy}$, the retrovirus associated with the disease known as adult T-cell leukaemia or ATL (see Nature 14 April, p.567). The occurrence of some such virus was first recognized in south-west Japan, and it has now been fully characterized as HTLV (for human $\mathrm{T}$-cell leukaemia virus) in $\mathrm{Dr}$ Robert Gallo's laboratory at the US National Cancer Institute. An important group of papers has now appeared (see Science 20 May) which confirms that HTLV is indeed somehow linked with
AIDS. Tantalizingly, however, these reports fall short of demonstrating that HTLV is the causative agent.

The new developments are nevertheless a significant pointer to the way in which the extra funds should be spent. Several suggestive and important pieces of information have come to light, largely as the result of work at the laboratories of $\mathrm{Dr}$ Max Essex at the Harvard School of Public Health and of Dr Robert Gallo at the National Cancer Institute, with the usual invaluable support of the Centers for Disease Control at Atlanta and with the collaboration of the Pasteur Institute in Paris. The most striking of the conclusions now reported are the following:

- Nineteen out of 75 male homosexuals suffering from AIDS have been found to carry antibodies against the surface antigens of a $\mathrm{T}$-cell line infected with HTLV, as did six out of 23 patients with lymphoadenopathy, thought to be a precursor form of AIDS (M. Essex et al., Science 220, 859; 1983). By the same criteria, the occurrence of antibodies among matched control groups turned out to be numerically negligible but not entirely zero (one out of 81 matched male homosexuals).

- Two patients (both black) with AIDS have been shown to harbour in the DNA of their lymphocytes the now well characterized cellular version of the DNA sequence of HTLV (Edward P. Gellmann et al., Science 202, 863; 1983). But the patients carrying the viral sequences were found only after an investigation of 33 patients suffering from AIDS. Mostly, HTLV could not be found.

- Both at the National Cancer Institute and the Pasteur Institute, it has been possible to isolate viruses which are either identical with or closely related to HTLV from the lymphocytes of patients (R.C. Gallo et al., Science 202, 865; 1983 and F. Barre-Sinoussi et al., Science 202, 868; 1983). In one case, the virus appears identical with one of the two known forms of HTLV; in the other (at Paris) the virus is closely related to HTLV but distinct from the forms so far characterized.

The significance of these developments is for the time being unclear, partly because the whole field is so new. But if the known virus were the causative agent of AIDS, it would be expected that antibodies would occur in all patients, not just a quarter of them. It is possible, of course, that the assay system, involving as it does novel manipulations of T-cell systems, may be less than fully efficient, but that would be surprising. On this evidence alone, there is nothing to deny the alternative explanation that infection by HTLV is not so much the cause but a consequence of AIDS. But that also stretches credulity.

The other two findings are, for the time being, similarly equivocal. If HTLV were the cause of AIDS, would one not expect the viral genome to occur more frequently than in two out of 33 patients? Not necessarily, for if the precipitating defect of AIDS is a deficiency of helper T cells, there may be only a fleeting moment, during the early development of the syndrome, when there are enough cells carrying the integrated cellular form of the viral genome for detection to be possible. But the isolation of viruses (whose viral characteristics have been fully demonstrated by showing that they are indeed infectious) from the lymphocytes of two patients must strengthen the suspicion that there is a link of some kind between the virus and the syndrome. The French result also points to the likelihood that all the members of the HTLV family have not yet been found and to the possibility that in real life the constitution of the virus may be unusually labile.

These developments therefore suggest a host of ways in which a modest $\$ 14.5$ million might be spent. The search for antibodies among representative samples of the groups which are apparently susceptible to AIDS is plainly an urgent matter. So too is an investigation of links between viruses such as HTLV and two other groups or viruses - those, such as cytomegalovirus, which are thought to be implicated in Kaposi's sarcoma and those such as the cat leukaemia virus which similarly appear to affect the T-cell balance of the cat. No doubt this is where some of the extra funds will go.

It would be wrong, however, to expect that these investigations by themselves will be sufficient, at least while two other basic questions remain unanswered. First, there is a need for a fuller understanding of the consequences of retroviruses capable of causing malignancy for the biology of an infected cell. Second, the biology of T-cells is yet to be fully described but is fortunately now the centre of many people's interest. And one of the materials found in recent years to stimulate the growth of classes of lymphocytes may turn out to be a palliative if not a cure.
John Maddox 